\title{
Nipple Deformity, CTCAE
}

National Cancer Institute

\section{Source}

National Cancer Institute. Nipple Deformity, CT CAE. NCI Thesaurus. Code C143706.

A disorder characterized by a malformation of the nipple. 